\title{
Schistosoma mansoni infection among preschool age children attending Erer Health Center, Ethiopia and the response rate to praziquantel
}

\author{
Makida Kemal ${ }^{1,4}$, Gemechu Tadesse $^{2}$, Adem Esmael ${ }^{1}$, Solomon Mequanente Abay ${ }^{3^{*}}$ (D) and Tadesse Kebede ${ }^{4}$
}

\begin{abstract}
Objective: Preschool age children (PSAC) are excluded from community based praziquantel treatment programs mainly due to paucity of evidence on the magnitude of schistosomiasis, efficacy and safety of this treatment in PSAC. The aim of this study is to assess Schistosoma mansoni infection rate and evaluate response to praziquantel in PSAC. A facility based longitudinal study was employed from April to June 2016 at Erer Health Center, Eastern Ethiopia. Stool sample was examined for schistosomiasis in 236 PSAC and repeated after 4 weeks post-treatment in positive individuals. Treatment outcomes were recorded and interpreted.

Results: Out of the 236 study participants, 59 (25\%) were infected with S. mansoni. Praziquantel treatment (40 mg/ $\mathrm{kg}$ ) resulted in $96.4 \%$ cure rate and $99.4 \%$ egg reduction rate. Children of 3-5 year old were significantly affected with S. mansoni infection. Nausea and fatigue were common mild adverse events within $4 \mathrm{~h}$ of treatment however moderate and severe adverse events and allergic reactions were not observed. In conclusion, praziquantel at $40 \mathrm{mg} / \mathrm{kg}$, the dose utilized in standard care for school age children, is tolerable and efficacious in the treatment of S. mansoni infection in PSAC, which calls for the healthcare system to provide appropriate service for this population.
\end{abstract}

Keywords: S. mansoni, Praziquantel, Pre-school aged children, Ethiopia

\section{Introduction}

Schistosomiasis is one of the most common parasitic diseases in many parts of Ethiopia, usually at an altitude between 1200 and $2000 \mathrm{~m}$ above sea level [1]. The anthelmintic drug praziquantel is the cornerstone for morbidity control with millions of people treated every year [2, 3]. It has been a drug of choice for schistosomiasis control for more than 40 years [4]. However, preschool age children (PSAC) are currently excluded from preventive chemotherapy control campaigns. The reasons for this exclusion include: PSAC to be considered at low risk of infection, insufficiency of evidence in safety and efficacy

\footnotetext{
*Correspondence: solomonabay@gmail.com

${ }^{3}$ Department of Pharmacology and Clinical Pharmacy, School of Pharmacy, College of Health Sciences, Addis Ababa University, Addis Ababa, Ethiopia

Full list of author information is available at the end of the article
}

of praziquantel for this age group [5] and lack of a pediatric formulation [6]. Recently, there is growing of evidence of infection in infants and young children in different parts of sub-Saharan African countries [7]. For instance a community based cross-sectional study in Northwest Ethiopia showed that $11.2 \%$ of PSAC are infected with S. mansonia [8]. The reported disease burden in this specific age group raise a concern of how the existing standard treatment of school aged children is extended to PSAC in high risk areas with the optimized dose of praziquantel.

Many studies showed that treatment with praziquantel is tolerable and efficacious in school age children (SAC) for the treatment of schistosomiasis [9]. Due to the limited evidence on the safety for children under 5 years of age at the moment, preventive chemotherapy for schistosomiasis is not indicated for this age group in many countries [10]. Although PSAC may also be at risk of 
schistosomiasis similar to SAC and can be infected very early in childhood, to authors' knowledge the efficacy and tolerability for praziquantel in the treatment of Schistosoma mansoni infection in young children in Ethiopia was not assessed. So, this study was aimed to assess S. mansoni infection in PSAC and the response rate for praziquantel treatment $(40 \mathrm{mg} / \mathrm{kg})$.

\section{Main text \\ Methods \\ Study design}

A facility based longitudinal study was employed. A facility based screening and follow-up were arranged to ensure that the PSAC, minor study participants, are under proper standard care.

\section{Study site and study population}

The study was conducted at Erer Woreda Health Center, Shinile Zone of Somali Region, Ethiopia from April to June 2016 having catchment population of 77,628 at Erer district according to national census in 2007 [11]. The average elevation of this district is 824 meters above sea level [12]. In this district, more than $89.6 \%$ of housing units get drinking water from well, spring, river and lake. River is one of the main source of drinking water with easy access to children main [11].

All PSAC who visited Erer Health Center for different medical reasons during the study period were included. A total of 236 children were screened for S. mansoni eggs. Those participants who are positive for the test were treated with praziquantel $40 \mathrm{mg} / \mathrm{kg}$ and followed for a month to assess the treatment outcome.

\section{Inclusion and exclusion criteria}

Inclusion criteria PSAC less than 6 years of age, whose parents gave written informed consent for the study.

Exclusion criteria PSAC who were treated with praziquantel within a month time of study recruitment period.

\section{Data collection techniques and clinical assessments}

All demographic and clinical information were recorded on a standard record form. Interviews were conducted by nurses at the Health Center. Information on health condition of children and adverse events after treatment were included in the interview. Mothers/guardians of children were interviewed at 4 and $24 \mathrm{~h}$ post treatment to assess tolerability of praziquantel.

\section{Stool sample collection and laboratory procedures}

Stool samples were collected initially once per day for two consecutive days and on day 28 and day 29 for reassessment to evaluate drug response. Parasitological diagnosis of $S$. mansoni was performed using double
Kato-Katz thick smears preparation at the Health Center Laboratory. The number of $S$. mansoni eggs were counted and recorded.

\section{Dosing and treatment procedure}

Children with positive stool examination for S. mansoni who were treated with the standard single dose praziquantel prepared by trained nurses according to weight-based guideline $(40 \mathrm{mg} / \mathrm{kg})$ were considered for follow-up. At each supervised drug administration by the health care providers, children were observed for $30 \mathrm{~min}$.

\section{Follow-up procedures}

Children who were enrolled in the study and treated with single dose of praziquantel were appointed for clinical assessments. Evaluations of adverse events were performed with parent/guardian report using standard list of praziquantel related adverse events at 4 and $24 \mathrm{~h}$ posttreatment follow-up. Stool examination was performed to determine egg reduction rate (ERR) and cure rate (CR) of praziquantel using the following formulas:

Cure rate

$$
\begin{aligned}
= & \left(1-\frac{\text { Number of S.mansoni negative participants }}{\text { Number of S.mansoni positive participants }}\right) \\
& \times 100
\end{aligned}
$$

ERR

$$
\begin{aligned}
= & \left(1-\frac{\text { Geometric mean of egg per gram after treatment }}{\text { Geometric mean of egg pergram before treatment }}\right) \\
& \times 100
\end{aligned}
$$

\section{Statistical analysis}

Data were recorded on standardized record forms and double entered to EPI data 3.1 and exported to SPSS software version 20 for analysis. Descriptive statistics were calculated for variables and bivariate analysis was conducted to check statistically significant association between variables. Geometric mean egg counts were calculated for participants who are positive for S. mansoni. It was categorized into infection intensities: light infections, 1-99 epg, moderate infections: 100-399 epg; and heavy infections: > $400 \mathrm{epg}$ according to $\mathrm{WHO}$ guidelines [10].

\section{Results}

Socio-demographic characteristics of the participant The mean age of 236 PSAC children included in the study was 3.38 (Standard deviation \pm 1.05 ) years, and majority of the study participants were at age 4 year $[\mathrm{n}=72,30.5 \%], 121$ were girls $(51.3 \%)$ and majority were from rural kebeles $[n=197,83.5 \%]$. Most of 
mothers/care givers of the study participants were $18-27$ years old [ $n=103,43.6 \%]$, house-wife [ $n=178$, $75.4 \%]$ and unable to write and read in educational status $[\mathrm{n}=103,43.6 \%$ ] (Tables 1 and 2).

\section{Schistosoma mansoni infection and associated factors}

Bivariate analysis was made for each explanatory variable of $S$. mansoni infection. Age, sex, address and frequency of taking children to river or pond during fetching water fulfill minimum condition for association. According to bivariate and multivariate analysis; age of children was significantly associated with $S$. mansoni infection in PSAC. Children at 5 year old age category were the most significantly associated with S. mansoni infection with $[\mathrm{AOR}=5.70,95 \% \mathrm{CI}(1.86$, 17.50), $\mathrm{p}=0.002$ ]. The more often children taken to river during fetching water were statistically associated with higher $S$. mansoni infection rate $[\mathrm{AOR}=3.86$, $95 \%$ CI $(1.86,17.28), \mathrm{p}=0.044$ ] (Tables 1 and 2$)$.

\section{Schistosoma mansoni infection rate}

Among PSAC screened for S. mansoni, 59 (25\%) were positive (Table 1). Of the 59 infected patients, 24 (40.7\%) had light and 35 (59.3\%) moderate S. mansoni infection. The overall mean egg count before treatment was 142.25 epg. The moderate intensity of $S$. mansoni infection in relation to sex was slightly higher among males 18 (30.5\%) than in females 17 (28.8\%) (Table 3). Only two cases were positive for S. mansoni 4 weeks post treatment. The pre-treatment geometric mean egg count for S. mansoni infection in PSAC was $204.92 \mathrm{epg}$ and reduced to $1.18 \mathrm{epg} 4$ weeks after treatment.

\section{Cure rate and egg reduction rate}

Cure rate after treatment was calculated as the percentages of individuals who were tested as S. mansoni egg free after treatment. The CR and the ERR were $96.4 \%$ and $99.42 \%$ respectively.

\section{Tolerability of praziquantel}

Most of the adverse events were observed within the first 4 hs after treatment. In this period, majority of the treated study participants experienced mild adverse events that include nausea [84.7\%], fatigue [84.7\%] and abdominal pain [72.9\%] (Additional file 1: Table S1).

\section{Discussion}

In the present study, prevalence of $S$. mansoni egg positivity among PSAC attending Erer Health center was $25 \%$. A cure rate of $96.4 \%$ was achieved by treating the PSAC that were found positive for schistosomiasis with the standard care intervention, praziquantel $40 \mathrm{mg} / \mathrm{kg}$. The egg reduction rate was $99.42 \%$.

The institution based prevalence of S. mansoni among PSAC was $25 \%$. This finding is similar to reports from cross-sectional survey conducted in Azaguie district of Côte d'Ivoire where the prevalence of $S$. mansoni among PSAC was $21.6 \%(n=160)$ [13]. The prevalence of $S$. mansoni egg positivity in Hamad Alla village, Sudan was 44.3\% $(\mathrm{n}=106)$ [14] and in Uganda studied in 7 lakeshore villages on 5 months to 7 year-old children was $37.7 \%(n=979)$ [15]. From a targeted epidemiological survey in Uganda, egg positivity rate was found to be

Table 1 Socio-demographic characteristics of preschool age children

\begin{tabular}{|c|c|c|c|c|c|}
\hline \multirow[t]{2}{*}{ Category } & \multicolumn{2}{|c|}{ S. mansoni infection } & \multicolumn{2}{|l|}{ OR $(95 \% \mathrm{Cl})$} & \multirow[t]{2}{*}{ P-value } \\
\hline & No. positive (\%) & Total $^{\mathbf{a}}(\%)$ & Crude & Adjusted & \\
\hline \multicolumn{6}{|l|}{ Age (years) } \\
\hline 2 & $6(9.7)$ & $62(26.3)$ & 1 & 1 & \\
\hline 3 & $18(29.0)$ & $62(26.3)$ & $3.82(1.39,10.43)$ & $5.05(1.72,14.80)$ & 0.003 \\
\hline 4 & $22(30.6)$ & $72(30.5)$ & $4.11(1.54,10.94)$ & $4.65(1.67,12.49)$ & 0.003 \\
\hline 5 & $13(32.5)$ & $40(16.9)$ & $4.49(1.54,13.11)$ & $5.70(1.86,17.55)$ & 0.002 \\
\hline Total & $59(25)$ & 236 & & & \\
\hline \multicolumn{6}{|l|}{ Sex } \\
\hline Boy & $32(27.8)$ & $115(48.7)$ & $1.34(0.74,2.42)$ & $1.60(0.84,3.03)$ & 0.149 \\
\hline Girl & $27(22.3)$ & $121(51.3)$ & 1 & 1 & \\
\hline \multicolumn{6}{|l|}{ Residence } \\
\hline Urban & $7(17.9)$ & $39(16.5)$ & 1 & 1 & \\
\hline Rural & $52(26.4)$ & $197(83.5)$ & $1.64(0.68,3.94)$ & $2.26(0.78,6.63)$ & 0.133 \\
\hline
\end{tabular}

a Total number of participants examined (\%) 
Table 2 Socio-demographic characteristics of parent/guardian of preschool age children

\begin{tabular}{|c|c|c|c|c|c|}
\hline \multirow[t]{2}{*}{ Category } & \multicolumn{2}{|c|}{ S. mansoni infection } & \multicolumn{2}{|l|}{ OR $(95 \% \mathrm{Cl})$} & \multirow[t]{2}{*}{ P-value } \\
\hline & No. Positive (\%) & Total $^{\mathrm{a}}(\%)$ & Crude & Adjusted & \\
\hline \multicolumn{6}{|l|}{ Age group } \\
\hline $18-27$ & $27(26.2)$ & $103(43.6)$ & 1 & 1 & \\
\hline $28-37$ & $19(25.3)$ & 75 (31.8) & $1.23(0.58,2.62)$ & $1.16(0.52,2.67)$ & 0.725 \\
\hline 38 and above & $13(22.4)$ & $58(24.6)$ & $1.17(0.52,2.63)$ & $1.17(0.49,2.77)$ & 0.728 \\
\hline \multicolumn{6}{|l|}{ Educational status } \\
\hline Illiterate & $24(23.3)$ & $103(43.6)$ & $2.17(0.25,18.15)$ & $0.51(0.19,1.31)$ & 0.160 \\
\hline Read and write & $23(24.7)$ & $93(39.4)$ & $2.30(0.27,19.69)$ & $0.52(0.19,1.34)$ & 0.175 \\
\hline Formal education & $12(30.0)$ & $40(16.9)$ & 1 & 1 & \\
\hline \multicolumn{6}{|l|}{ Ethnicity } \\
\hline Somali & $32(27.6)$ & $116(49.6)$ & 1 & & \\
\hline Oromo & $23(23.2)$ & $99(42.3)$ & $0.71(0.31-1.60)$ & $0.77(0.39-1.50)$ & 0.446 \\
\hline Amhara & $4(21.1)$ & $19(8.1)$ & $0.77(0.33,1.75)$ & $0.59(0.73,2.02)$ & 0.401 \\
\hline \multicolumn{6}{|l|}{ Marital status } \\
\hline Married & $56(25.9)$ & $216(91.5)$ & $1.43(0.35,5.90)$ & $1.27(0.27,5.91)$ & 0.765 \\
\hline Others & $3(15.0)$ & $20(8.5)$ & 1 & 1 & \\
\hline \multicolumn{6}{|l|}{ Occupation } \\
\hline Housewife & $47(26.4)$ & $178(75.4)$ & $0.73(0.35,1.49)$ & $1.034(0.23,4.63)$ & 0.999 \\
\hline Others $^{\mathrm{b}}$ & $12(20.7)$ & $58(24.6)$ & 1 & 1 & \\
\hline \multicolumn{6}{|c|}{ Frequency of using river/spring or pond water for bathing a child } \\
\hline Not at all & $16(23.2)$ & $69(29.2)$ & 1 & 1 & \\
\hline Sometimes & $32(23.7)$ & $135(57.2)$ & $1.03(0.52,2.04)$ & $1.22(0.55,2.72)$ & 0.627 \\
\hline Often & $11(34.4)$ & $32(13.6)$ & $1.74(0.69,4.35)$ & $2.15(0.69,6.65)$ & 0.183 \\
\hline \multicolumn{6}{|c|}{ Frequency of taking children to river/pond during fetching water } \\
\hline Not at all & $27(25.5)$ & $106(44.9)$ & 1 & 1 & \\
\hline Sometimes & $26(21.7)$ & $120(50.8)$ & $0.81(0.44,1.49)$ & $0.74(0.37,1.47)$ & 0.384 \\
\hline Often & $6(60.0)$ & $10(4.2)$ & $4.39(1.15,16.74)$ & $3.86(1.86,17.28)$ & 0.044 \\
\hline
\end{tabular}

a Total number of participants examined (\%)

b Others (merchant, employed and others)

Table 3 Intensity of Schistosoma mansoni among preschool age children

\begin{tabular}{llll}
\hline Variables & Light (1-99 epg) & $\begin{array}{l}\text { Moderate } \\
(\mathbf{1 0 0 - 3 9 9} \mathbf{e p g})\end{array}$ & Total \\
\hline Age (years) & & & \\
2 & $4(6.8 \%)$ & $2(3.4 \%)$ & $6(10.2 \%)$ \\
3 & $8(13.56 \%)$ & $10(16.9 \%)$ & $18(30.46 \%)$ \\
4 & $7(11.86 \%)$ & $15(25.4 \%)$ & $22(37.26 \%)$ \\
5 & $5(8.5 \%)$ & $8(13.56 \%)$ & $13(22.06 \%)$ \\
Sex & & & \\
Male & $14(23.72 \%)$ & $18(30.5 \%)$ & $32(54.22 \%)$ \\
Female & $10(16.94 \%)$ & $17(28.81 \%)$ & $27(45.75 \%)$ \\
\hline
\end{tabular}

44.3\% $(\mathrm{n}=131)$ at Lake Albert and $16 \%(\mathrm{n}=232)$ at Lake Victroria areas [16]. A cross sectional household based study conducted in Wondo Genet, Southern Ethiopia reveals that $37.2 \%$ of $S$. mansoni infection in under-five children [17]. The difference in rate of positivity among the reports might be due to difference in sampling population, study design and geographical settings.

The present study showed that children at the age of five were more likely infected with $S$. mansoni compared to lower age groups. A similar study conducted in Ugandan PSAC showed that children aged between 3 and 6 years had higher risk of infection than their younger counterparts [16]. This might be due to high frequency of water body contact with the aforementioned age groups. The current study shows that children who were often taken to river during fetching water were three times more likely infected with $S$. mansoni compared to those not taken at all.

In the current study praziquantel achieved CR of $96.4 \%$ against S. mansoni infections 4 weeks after treatment among PSAC. Cure rate of this study was higher than that of study conducted in Uganda 77.6\% [15], study in districts of Côte d'Ivoire 88.6\% [5] and Sudan 90.5\% [14]. 
We found that praziquantel ERR after 4 weeks of treatment in PSAC was $99.4 \%$. Whereas, a study conducted in Uganda with a follow up of 3-4 weeks showed ERR of $99.1 \%$ [15] and Cote d Ivoire with a follow up period of 3 weeks was 96.7\% [5]. The differences in ERR and CR might be due to difference in the time to evaluate treatment efficacy, the presence of a large number of immature worms, intensity of transmission and intensities of pretreatment egg loads.

In conclusion, the study revealed that a quarter of screened PSAC are positive for $S$. mansoni infection. PSAC had low or moderate $S$. mansoni infection intensity, which responds to crushed praziquantel at a dose of $40 \mathrm{mg} / \mathrm{kg}$ with CR of $96.4 \%$. Though the study supports use of praziquantel in PSAC as recommended by WHO for preventive chemotherapy program in SAC, confirmatory large scale clinical studies are required to identify pharmacokinetic and pharmacodynamic determinants to improve patient outcomes.

\section{Limitation of the study}

The main limitation is that samples come from children that attend the health facility, and therefore extrapolating the percentage infected to the general population as a whole is unjustified.

\section{Additional file}

Additional file 1: Table S1. Reported adverse events within 4 and $24 \mathrm{~h}$ post-treatment of praziquantel.

\section{Abbreviations}

AOR: adjusted odds ration; CR: cure rate; epg: eggs per gram; ERR: egg reduction rate; PSAC: pre-school age children; SAC: school age children; WHO: World Health Organization.

\section{Authors' contributions}

MK, TK, AE and SMA conceived and designed the study, performed analysis and interpretation of the data. MK led the study. MK, TK and AE drafted the manuscript; GT and SMA critically reviewed the manuscript. All authors read and approved the final manuscript.

\section{Author details}

${ }^{1}$ School of Medicine, Goba Referral Hospital, Madda Walabu University, Bale Robe, Ethiopia. ${ }^{2}$ Ethiopian Public Health Institute, Addis Ababa, Ethiopia. ${ }^{3}$ Department of Pharmacology and Clinical Pharmacy, School of Pharmacy, College of Health Sciences, Addis Ababa University, Addis Ababa, Ethiopia. ${ }^{4}$ Department of Microbiology Immunology and Parasitology, School of Medicine, College of Health Sciences, Addis Ababa University, Addis Ababa, Ethiopia.

\section{Acknowledgements}

We thank Somali Regional State Health Bureau and Erer Health Center staff for their contribution during data collection. Our regards also extends to the study subjects for willingness and participation in the study.

\section{Competing interests}

The authors declare that they have no competing interests.

\section{Availability of data and materials}

Data will be available up on request.

\section{Consent for publication}

Not applicable.

\section{Ethics approval and consent to participate}

Ethical approval was obtained from Department Ethics Review Committee of the Department of University with Ref. No.: DRERC/003/08, on date: Feb. 01/2016. Permission letter was obtained from Regional and Zonal Health Offices, and Erer Woreda Health Office Administration. A written informed consent was obtained from parents/guardians after thorough information was given on the aim and procedures of the study. Study participants positive for S. mansoni and intestinal parasites were treated accordingly by the health center professionals.

\section{Funding}

Addis Ababa University, Graduate Studies and Ethiopian Public Health Institute supported the research. The funder has no role in the design of the study and collection, analysis, and interpretation of data and in writing the manuscript.

\section{Publisher's Note}

Springer Nature remains neutral with regard to jurisdictional claims in published maps and institutional affiliations.

Received: 28 February 2019 Accepted: 1 April 2019

Published online: 05 April 2019

\section{References}

1. Worku L, Damtie D, Endris M, Getie S, Aemero M. Asymptomatic malaria and associated risk factors among school children in Sanja Town, Northwest Ethiopia. J Parasitol Res. 2014;2014:1-6.

2. Fenwick A, Webster J, Bosque-Oliva E, Blair L, Fleming F, Zhang Y, et al. The Schistosomiasis Control Initiative (SCI): rationale, development and implementatin from 2002-2008. Parasitol. 2009;136:1719-30.

3. Utzinger J, Keiser J. Schistosomiasis and soil-transmitted helminthiasis: treatment and control. Expert Opin Pharmacother. 2004;5:263-85.

4. Bergquist R, Utzinger J, Keiser J. Controlling schistosomiasis with praziquantel: how much longer without a viable alternative? Infect Dis Poverty. 2017;6:74.

5. Coulibaly JT, N'gbesso YK, Knopp S, Keiser J, N'Goran EK, Utzinger J. Efficacy and safety of praziquantel in preschool-aged children in an area co-endemic for Schistosoma mansoni and S. haematobium. PLoS Negl Trop Dis. 2012;6:e1917.

6. Won KY, Kanyi HM, Mwende FM, Wiegand RE, Goodhew EB, Priest JW, et al. Multiplex serologic assessment of schistosomiasis in Western Kenya : antibody responses in preschool aged children as a measure of reduced transmission. Am J Trop Med Hyg. 2017;96:1460-7.

7. Ekpo U, Oluwole A, Abe E, Etta H, Olamiju F, Mafiana C. Schistosomiasis in infants and pre-school-aged children in sub-Saharan Africa. Parasitology. 2012;139:835-41.

8. Alemu A, Tegegne Y, Damte D, Melku M. Schistosoma mansoni and soiltransmitted helminths among preschool-aged children in Chuahit, Dembia district, Northwest Ethiopia : prevalence, intensity of infection and associated risk factors. BMC Public Health. 2016. https://doi.org/10.1186/ s12889-016-2864-9.

9. World Health Organization. Investing to overcome the global impact of neglected tropical diseases: third WHO report on neglected tropical diseases?. Geneva: World Helath Organization; 2015.

10. World Health Organization. Preventive Chemotherapy in Human Helminthiasis. Geneva: World Helath Organization; 2006.

11. Central Statistical Agency. Census-2007 report [Internet]. 2007. http:// www.csa.gov.et/census-report/complete-report/census-2007. Accessed 15 Mar 2019. 
12. World Heritage Encyclopedia. Erer (Woreda) [Internet]. 2019. http://www. worldlibrary.org/Article.aspx?Articleld=0007386407\&Title=erer(woreda). Accessed 19 Mar 2019.

13. Coulibaly JT. Epidemiology and diagnosis of schistosomiasis in preschoolaged children in Azaguié, south Côte d 'Ivoire. Basel: University of Basel; 2013.

14. Amin MA, Swar M, Kardaman M, Elhussein D, Nouman G, Mahmoud A, et al. Treatment of pre-school children under 6 years of age for schistosomiasis: safety, efficacy and acceptability of praziquantel. Sudan JMS 2012;7:67-76.

15. Sousa-Figueiredo JC, Betson M, Atuhaire A, Arinaitwe M, Navaratnam AMD, Kabatereine NB, et al. Performance and safety of praziquantel for treatment of intestinal schistosomiasis in infants and preschool. PLoS Neg Trop Dis. 2012;6:e1864.

16. Sousa-Figueiredo CJ, Pleasant J, Day M, Betson M, Rollinson D, Montresor A, et al. Treatment of intestinal schistosomiasis in Ugandan preschool children: best diagnosis, treatment efficacy and side effects, and extended praziquantel dosing pole. Int Health. 2010;2:103-13.

17. Nyantekyi LA, Legesse M, Belay M, Tadesse K, Manaye K, Macias C, et al. Intestinal parasitic infections among under-five children and maternal awareness about the infections in Shesha Kekele, Wondo Genet, Southern Ethiopia. Ethiop J Heal Dev. 2010;24:185-90.
Ready to submit your research? Choose BMC and benefit from:

- fast, convenient online submission

- thorough peer review by experienced researchers in your field

- rapid publication on acceptance

- support for research data, including large and complex data types

- gold Open Access which fosters wider collaboration and increased citations

- maximum visibility for your research: over $100 \mathrm{M}$ website views per year

At BMC, research is always in progress.

Learn more biomedcentral.com/submissions 